\title{
TRANSCULTURALIDADE ETRÂNSITOS INTERSEMIÓTICOS: ADAPTAÇÕES E TRANSCRIAÇÕES CINEMATOGRÁFICAS EM GRACILIANO RAMOS
}

\author{
Claudio Cledson Novaes ${ }^{1}$ \\ Marcos Cézar Botelho de Souza ${ }^{2}$
}

\begin{abstract}
Resumo: Discutimos neste artigo como a obra de Graciliano Ramos apresenta ao leitor atual aspectos potenciais para se pensar a mobilidade cultural na contemporaneidade, seja no campo estético do trânsito intersemiótico na relação entre literatura e cinema; seja no campo ético do transe que amplifica a memória cultural, quando reencenamos a leitura da obra do escritor alagoano como rasura da tradição literária nacional denominada de regionalista, para alcançarmos a amplitude de uma narrativa que transborda para o global e dilui as fronteiras discursivas tradicionais, ao encenar ao leitor e espectador a memória como traço diaspórico, transcultural e nômade.
\end{abstract}

Palavras-chaves: Literatura; Cinema; Graciliano Ramos; Adaptação; Transcriação.

\section{TRANSCULTURALITY AND INTERSEMIOTIC TRANSIT: CINEMATOGRAPHIC ADAPTATIONS AND TRANSCRIATIONS IN GRACILIANO RAMOS}

\begin{abstract}
We discuss in this article how the work of Graciliano Ramos presents to the current reader potential aspects to think about cultural mobility in contemporaneity; either in the aesthetic field of intersemiotic transit in the relation between literature and cinema, or in the ethical field of the trance that amplifies the cultural memory, or when we reenact the writer's work as a erasure of the national literary tradition, known to be regionalist, in order to reach the amplitude of a narrative that overflows to the global space and dilutes traditional discursive frontiers, while enacting memory to the reader and spectator as a diasporic, transcultural and nomadic trait.
\end{abstract}

Keywords: Literature; Cinema; Graciliano Ramos; Adaptation; Transcreation.

\footnotetext{
1 Doutor em Ciências da Comunicação (ECA/USP), Pós-Doutorado em Comunicação (ECO/UFRJ). Professor da Universidade Estadual de Feira de Santana/Pesquisador do Programa de Pós-Graduação em Estudos Literários: ccnovaes.ues@gmail.com.

2 Doutor em Literatura e Cultura (UFBA). Professor da Universidade Estadual de Feira de Santana/Pesquisador do Programa de Pós-Graduação em Estudos Literários: marcosbotelho.br@gmail.com.
} 


\section{Situando a obra de Graciliano Ramos a partir da contemporaneidade}

A obra literária de Graciliano Ramos requer leitura atual que aponte para outras perspectivas de diálogos estéticos e éticos, seja mapeando as distensões políticas das suas narrativas literárias, em relação os modelos do regionalismo modernista do século $\mathrm{XX}$, seja discutindo os paradigmas modernos do cinema mundial que, ao serem apropriados pelo cinema brasileiro, permitiram extrair dos seus livros potências cinematográficas de transe cultural e de performances intersemióticas.

Ao lermos as margens da obra de Graciliano Ramos encontramos diversos suplementos, textos marginais, lances autobiográficos, depoimentos acerca de seu tempo, cartas memoráveis aos amigos e à esposa, entrevistas, manuscritos e, sobretudo, uma fundamental trilogia fílmica, que tecem uma rede amplificadora da sua assinatura para além da ficção literária canonizada, a ponto de apenas as teorias e críticas mais recentes do século XXI possibilitar compreender os significados ainda ativos de sua literatura e dos filmes dela adaptados.

Esta reflexão abre um debate teórico mais amplo acerca dos estudos das relações entre a literatura e o cinema moderno no Brasil, no campo das representações das memórias locais brasileiras em transe e os trânsitos que situam estas memórias regionais no âmbito nacional e global, a partir da problematização dos valores transculturais e dos hibridismos pós-coloniais que se insinuam em novas leituras da obra de Graciliano Ramos. As imagens de nomadismos e de fronteiras, de hibridismos e de diásporas são polêmicas atuais e instigantes que o conjunto da sua obra mobiliza na literatura no trânsito da literatura para obras seminais do cinema moderno brasileiro.

Os filmes transpostos de seus livros contribuem ainda hoje como força narrativa dissonante das leituras mais tradicionais do regionalismo literário de 1930. Estas narrativas cinematográficas são pensadas aqui como signos de movimento irrefreável de deslocamentos culturais ativados pelas transformações políticas, para o questionamento das "velhas identidades" e, principalmente, para rever os sintomas das relações contemporâneas entre as culturas nacionais - antes mais facilmente identificadas em termos como terceiro mundo, centro e periferia, que são cada vez mais postos em questão 
pelas diásporas atuais. Para Iain Chambers, essas representações nos dizem que:

\begin{abstract}
quando o 'Terceiro Mundo' já não pode se manter em um remoto 'lá' e começa hoje a aparecer 'aqui'; quando o choque entre culturas, histórias, religiôes e línguas diferentes já não ocorre na periferia, nas 'zonas de contato', com as denomina Mary Louise Pratt, mas irrompe no centro de nossa vida cotidiana, nas cidades e culturas do chamado 'primeiro' mundo ou mundo 'desenvolvido', então, quiçá, podemos começar a falar de uma interrupção significativa do sentido anterior de nossas vidas, culturas, línguas e de nossos futuros (CHAMBERS, 1994, p. 14).
\end{abstract}

Inicialmente, o conceito de diáspora, suplementado por vários autores para compreender os deslocamentos identitários atuais, é de grande importância para a análise das narrativas de literárias de Graciliano Ramos, assim como para pensar o processo de transcriação das obras cinematográficas adaptadas de seus livros. A diáspora é pensada para além dos seus lugares-matrizes, inicialmente relacionados às dispersões dos gregos e armênios e às experiências e vicissitudes dos judeus e, mais tarde, transposta comparativamente aos deslocamentos forçados de africanos para as colônias escravistas. No âmbito dos estudos da migração pós-colonial, diáspora é um conceito-chave que se estende à compreensão e descrição das experiências de numerosos grupos étnicos contemporâneos, que pode ser associada aos sertanejos e seus antípodas recodificados na obra de Graciliano Ramos. O termo diáspora - como outras chaves conceituais emergentes no léxico teórico, como hibridização, mundialização, globalização, nomadismo, disseminação e tradução intercultural, etc. - é especialmente importante para ler contemporaneamente as narrativas do escritor alagoano, por trazer as marcas da potência constitutiva das dispersões de populações e das culturas contemporâneas mais do que a radicação e sedentarização das identidades.

Se historicamente as conotações da diáspora e da migração tinham valor negativo, associadas ao exílio forçado, à alienação e à perda do lugar de origem, a leitura que se pretende fazer da "diáspora brasileira" sintoniza-se com as recodificações mais produtivas dos termos (BRAZIEL; MANNUR, 2009; GILROY, 2001), tomando as narrativas de migrantes como testemunhos "dessencializadores" da identidade brasileira no cenário da mundialização cultural. Embora muitas experiências migrantes sejam marcadas pelas 
tensões e pela ansiedade da transição identitária, podem também "se tornar fontes veementes da criatividade e do dinamismo que produzem na literatura e no cinema [...] identidades híbridas, sincréticas, reais ou virtuais" (NAFICY, 2010, p. 143).

\section{Rasuras da obra de Graciliano Ramos no contexto cultural brasileiro}

Nos recortes historiográficos da moderna tradição literária no Brasil, a obra de Graciliano Ramos está, via de regra, situada numa comunidade que une escritores e intelectuais como Jorge Amado, José Lins do Rego, Rachel de Queiroz, entre outros. Suas produções estão inseridas, por conseguinte, naquilo que se convencionou chamar de "Romance de 30", um vetor "regional" do modernismo brasileiro, abrangendo autores e pensadores diversos que convergiram para uma agenda comum: redescobrir e exteriorizar o interior da nação, notadamente a partir do recém-inaugurado Nordeste.

Tomada como objeto do discurso por escritores engenhosos, a geografia física e humana do Nordeste seria representada “diretamente”, com suas mazelas, misérias, contradições e tradições arruinadas, para trazer à cena do imaginário brasileiro - sem as tintas idealistas do regionalismo romântico - os sujeitos esquecidos pela grande narrativa nacional. Na virada para a década de 30, o advento de uma sociedade mais complexa e a modernização desigual - assim como os problemas decorrentes da definitiva centralização política e econômica no Sudeste do país - fizeram emergir um romance regionalista cuja missão era explicar e entender a nação a partir de dados retirados dos saberes da sociologia, da história, da etnografia, da geografia, da ecologia etc. Contudo, a obra de Graciliano Ramos, focalizada na sociedade nordestina em reconfiguração, mobiliza forças culturais em transes éticos e estéticos dissonantes que rasuram a restritiva comunidade do chamado "romance regionalista".

De fato, os romancistas de 30 trataram de temas semelhantes aos do autor alagoano, em um mesmo ambiente intelectual e participaram ativamente daquela formação discursiva que Durval Muniz de Albuquerque Jr. faz emergir no seu livro: A Invenção do Nordeste e outras artes. Este último sintagma, a invenção do Nordeste, que aproxima uma faculdade do discurso a uma sigla geográfica que tomamos como atemporal, certamente causará 
algum desconforto, mas pode ser outro operador de leitura bastante produtivo para explicar os deslocamentos que as adaptações fílmicas fazem das obras de Graciliano Ramos. Segundo Alburquerque Jr., a invenção do Nordeste deu-se com a emergência discursiva de uma geografia imaginária que se materializou como produção histórica sobre um espaço social e afetivo, a região do Nordeste, principalmente durante as primeiras décadas do século XX. Partindo de uma análise arqueológica dos discursos de criação do Nordeste, o autor descreve as estratégias enunciativas das narrativas e representações que naturalizaram características, estereótipos, atributos estéticos e morais, culturais e simbólicos, que deliberaram por uma “identidade nordestina". Ou seja: o Nordeste nasce, segundo o autor, quando "se encontram poder e linguagem, onde se dá a produção imagética e textual" que criou formas de dizibilidade e visibilidade de um referente dado como fixo.

Em outras palavras, o Nordeste não é uma entidade surgida por combustão espontânea, nem germinada da terra agreste. Embora acreditemos que a região nordestina seja uma unidade perene e natural, até meados da década de 20, o Nordeste não existia, já que o território nacional se dividia, basicamente, entre Sul e Norte.

Ainda conforme Albuquerque Jr., em plena crise do poderio econômico e social das oligarquias regionais, os representantes políticos do Norte, antes dispersos, começaram a se agrupar em torno de um repertório que sensibilizasse a opinião pública nacional: a seca, o cangaço, o messianismo, as lutas de parentelas pelo controle do Estado, formando uma vasta rede discursiva, cujos temas "fundaram" a região, "uma área de poder que começa a ser demarcada com fronteiras que servirão de trincheiras para a defesa de privilégios ameaçados". Porém, o que mais nos interessa na Invenção do Nordeste é a tese de que "a elaboração da região se dá no plano cultural, mais do que no plano político [...] e no esforço de criar novos territórios existenciais e sociais, capazes de resgatar o passado de glória da região, o fausto da casa-grande, a docilidade da senzala, a paz e estabilidade do Império". Assim, o Nordeste, segundo o historiador, "é gestado e instituído na obra sociológica de Gilberto Freyre, nas obras de romancistas como José Américo de Almeida, José Lins do Rego, Rachel de Queiroz; na obra de pintores como Cícero Dias, Lula Cardoso Ayres; na música de Luiz Gonzaga etc. O Nordeste é gestado como espaço da saudade dos tempos de glória, saudades do 
engenho, da sinhá, do sinhô, da Nega Fulô, do sertão e do sertanejo puro, a força telúrica da região" (Albuquerque Jr., 2001, p. 35)

\section{Estilhaços da obra de Graciliano Ramos para além do regionalismo no cinema}

Mas como a obra de Graciliano se (des)encaixa nessa zona discursiva? E como as adaptações fílmicas de suas obras participam e tensionam essa discursividade acerca do Nordeste, e qual lugar de trânsito cultural que a obra do autor ocupa na historiografia literária? O Romance de 30 foi fundamental na produção e fixação do referente Nordeste. De fato, essa máquina discursiva não somente representou este objeto, a região nordestina, mas o inventou à medida que o representava. O Romance de 30, juntamente com o discurso nacional-popular, emergiu em simultaneidade à invenção do "Sul" como centro do poder nacional, enquanto criava seu "outro", o Nordeste (que por sua vez inventava seu "outro", o Sul). Entretanto, como sugere o próprio Muniz de Albuquerque, o romance de 30, a despeito de ser conciliatório, "não é monolítico, no que tange à sua visão do Nordeste, da construção desta região como espaço da saudade e da tradição".

Se o Romance de 30 dará forma literária à formação discursiva que chamamos de Nordeste, o movimento do Cinema Novo, que terá na obra de Graciliano Ramos um dos referenciais basilares de seu programa estético e ideológico, será responsável por plasmar, em outra quadra histórica, as imagens em movimento da cultura nordestina no imaginário nacional.

Além do diálogo com as obras de interpretação sociológica do Brasil, o Cinema Novo estabeleceu com o Modernismo brasileiro uma relação intensa, buscando em suas experiências formais e estéticas, principalmente no Romance Social de 30, as imagens e enunciados que falavam da realidade social do País. Como desdobramento do projeto modernista, o Cinema Novo buscava também a aproximação entre arte e sociedade, inserindo-se, portanto, no empenho dos intelectuais e artistas pela transformação social. Nesse sentido, o movimento levou adiante a concepção modernista de "redescobrir o País" e as "raízes da identidade nacional", realizando em suas obras uma releitura imagética do Brasil, principalmente do Nordeste literário, já representado no "estilo cinematográfico" de escritores como Graciliano Ramos, José Lins do Rego e Jorge Amado. Foram justamente os cineastas do 
Cinema Novo, notadamente Nelson Pereira dos Santos e Leon Hirszmam, que transpuseram, com grande êxito, três obras de Graciliano Ramos para o cinema.

Os principais filmes do Cinema Novo, mesmo que não sejam adaptações diretas do cânone literário, já que valorizavam a "política dos autores cineastas", estabeleceram um modo diferencial de contato com a literatura de 30: retomam o texto literário, mas vão além da transposição literal, reescrevendo-os com vistas a suplementar a matéria literária.

Esse é o caso de Vidas Secas (1963), de Nelson Pereira dos Santos, obra orientadora da estética cinemanovista, que atualiza a pauta do livro de Graciliano Ramos às questões políticas do presente em que foi realizada. Assim, logo no prólogo, o diretor adverte o espectador, em tom programático, que seu "filme não é uma transposição fiel para o cinema de uma obra imortal da literatura brasileira. É um depoimento sobre a dramática realidade social de nossos dias e extrema miséria que escraviza 27 milhões de nordestinos e que nenhum brasileiro digno pode ignorar". Ou seja: ao retomar o livro de 1938, Vidas Secas, de Nelson Pereira, mesmo rente ao romance, se propunha a ser mais uma intervenção na agenda política dos anos 1960, marcada pelas discussões sobre a reforma agrária, as ligas camponesas, a estrutura social do interior brasileiro e as migrações internas de nordestinos, do que uma adaptação "fidedigna" ao livro.

O filme narra a saga de uma família de retirantes nordestinos que, tangidos pela seca, migram do sertão à cidade. Para reiterar o aspecto cíclico da vida dos deserdados do sertão, o filme começa e termina com a família de Fabiano deslocando-se em busca de trabalho. No nível formal, o diretor privilegia, logo na sequência de abertura, a utilização de grandes planos gerais da geografia do sertão nordestino, enquanto a banda sonora reproduz os sons monocórdios de um carro de boi, acompanhando a dolorosa caminhada da família até o primeiro plano da imagem ou para o fundo, na sequência final. Decupagem, angulações, planificação, sons e mise-en-scène não somente narram, em imagens e sem o auxílio da palavra, a "entrada" e a "fuga" dos personagens num espaço que já conhecemos, a realidade da seca no Nordeste, mas transpõe para a linguagem cinematográfica a estrutura espiral e cíclica do texto literário, já que tanto romance quanto o filme narram um processo de repetição, o ciclo determinista da seca, e o devir dos personagens. 
A possibilidade de conscientização política de Fabiano é esboçada justamente numa adição que o filme faz ao livro. Após ser preso e humilhado pelo Soldado Amarelo, Fabiano ganha a liberdade e acompanha um grupo de cangaceiros ao qual pertence seu companheiro de cela. Em uma bifurcação da estrada, os cangaceiros tomam um caminho à esquerda; Fabiano, a esposa, sinha Vitória, e os dois filhos rumam no caminho oposto. Fabiano, armado como cangaceiro e montado num cavalo, é visto em contraplongê, silhuetado contra o céu, o que, por um momento, confere à sua figura uma linha de fuga e uma dimensão imponente. Visto assim, Fabiano é representado como um herói positivo e, aparentemente, seduzido pela tomada de consciência ideológica. Contudo, Fabiano hesita e seu olhar vasculha a cena, a paisagem, os cangaceiros, a família, até que a câmera muda de ângulo novamente. Ao mostrá-lo em contraplongê, em ângulo de baixo para cima, Nelson Pereira acrescenta na trilha sonora os ruídos de um cincerro que lembra Fabiano de sua condição de vaqueiro. Nesse momento e após sentir o impasse entre se engajar no cangaço e permanecer junto à família, Fabiano decide seguir para casa.

À época da aparição do romance, vista como "reacionária" por quadros do Partido Comunista, por Graciliano Ramos não ter efetivado a conversão de Fabiano à luta popular, como prescreviam as normas da "estétia socialista”, essa sequência, conforme Tolentino, servia tanto de recado aos poderes estabelecidos - a violência desmedida contra homens indefesos e corretos como Fabiano, acrescidas da exploração econômica, podiam levar homens dignos como o sertanejo do filme a uma ação armada primitiva e desmedida -, como uma crítica velada à opção pela luta armada quando do momento da realização do filme. Essa passagem é mais intensa no filme do que no livro, no qual Fabiano vive uma rebelião apenas vicariamente, digamos, somente em "pensamento", tomado pelo ódio e pelos efeitos da aguardente. Aqui, as lentes do engajamento do Cinema Novo sugerem que a possibilidade de Fabiano entrar para o cangaço, como metáfora da luta armada, seria também uma opção revolucionária possível. Não por acaso, há um diálogo secreto e discursivo entre a versão fílmica de Vidas Secas e Deus e o Diabo na Terra do Sol, de Glauber Rocha. Podemos dizer que Manuel, o protagonista de Deus e o Diabo na Terra do Sol, é um avatar de Fabiano que realiza seu devir revolucionário e atinge a consciência sediciosa, rumando em 
direção à superação da marginalidade e da opressão, como a ontológica sequência final do filme de Glauber Rocha sugere.

Em 1972, o cineasta Leon Hirszmam adaptou o romance São Bernardo, cuja primeira edição é de 1934. Do ponto de vista da forma, o filme de Hirszman talvez seja a mais radical das três traduções de Graciliano Ramos para o cinema e aquela que ajudou a elevar o padrão estético da cinematografia nacional, propondo uma correlação entre produtos culturais acessíveis ao grande público e a qualidade formal do "cinema de arte". São Bernardo, como afirma Ismail Xavier, "oferece um exemplo de estratégias típicas de um cinema moderno disposto a explorar as possíveis disjunções entre som e imagens, entre o olhar e a voz numa adaptação" (XAVIER, p. 129).

Para dialogar com o romance, Hirszman privilegiou o uso de planos fixos e de longa duração, valorizando o ritmo pausado da prosa do protagonista, Paulo Honório. A utilização de planos estáveis e temporalmente extensos estava de acordo com uma tendência do moderno cinema europeu da época, sobretudo com as obras de Jean-Marie Straub e Andrei Tarkovski, uma concepção que vê na fixidez e na imagem-tempo dos planos de longa duração uma atitude ideológica contra o "cinema clássico" de não picotar a mise-en-scène, permitindo que o acaso e o tempo real fluam livremente no filme. Segundo o cineasta,

\begin{abstract}
parte do filme tem a câmera imóvel, parte do filme tem a câmera em movimento, mas a imagem não se move no sentido em que o movimento é ornamento que já vive por si. Evitei tudo o que pudesse enganar o espectador, que pudesse fazer com que simplesmente a emoção abarcasse todos os níveis da razão, Quer dizer, impedir que os sentimentos tirem toda a possibilidade de ligação dialética entre a razão e o sentimento. Em certos momentos, isto é procurado na longa duração do plano, isto é, nas relações da fotografia e da montagem para movimentar esta relação de conflito com o espectador. (Apud SALEM, 1997, p.200).
\end{abstract}

Até mesmo a inserção da música no filme, um "ornamento" extradiegético e, portanto, estranho ao universo romanesco de Graciliano, passa um tratamento disjuntivo em relação ao texto, mas, contraditoriamente, coerente com o drama dos personagens. A música que permeia São Bernardo aparece em momentos pontuais e foi composta por Caetano Veloso a partir de uma interpretação improvisada de Rojão do eito, um canto de trabalho de lavradores rurais, feita de gemidos paramelódicos. A 
forma musical de lamento, quase uma espécie de blues retirado das work songs dos escravos da diáspora negra, expande a dor dos personagens principais, servindo em muitas passagens de articulação entre as imagens de camponeses no eito e os monólogos densos dos protagonistas do filme.

De fato, Hirszman, mesmo abdicando de qualquer subserviência à transposição literal do romance, consegue traduzir em imagens e sons o estilo conciso e austero do livro, captando aquilo que Antonio Candido escreveu sobre romance, em "Os Bichos do subterrâneo", de Tese e Antítese, ensaio que, segundo o cineasta, foi "a base do roteiro do filme". Conforme Candido, "talvez não haja em nossa literatura outro livro tão reduzido ao essencial, capaz de exprimir tanta coisa em resumo tão estrito. Por isso é inesgotável seu fascínio, pois poucos darão, quanto ele, semelhante ideia de perfeição, de ajuste ideal entre os elementos que compõem um romance" (CANDIDO, 1964, p. 103).

Poucos filmes darão, quanto a obra de Hirszman, semelhante resolução de ajuste ideal entre os elementos que compõem o romance original e sua tradução em imagens fílmicas. Se por um lado, o cineasta afirma que procurou, de acordo com o estilo do autor alagoano, "tirar qualquer tipo de ornamento gramatical que pudesse impedir a compreensão de Graciliano", por outro, adita, pelo uso de uma linguagem cinematográfica rigorosa, passagens que não encontramos no romance, mas que traduzem uma leitura ampliada das questões tratadas no livro. O diretor recusa-se a transpor todo o conteúdo narrativo do romance para as imagens fílmicas. A estratégia mais importante do diretor no que tange às homologias foi importar os diálogos do livro para as cenas, tomando o romance, como afirmou, "como pesquisa, para saber o momento em que ia acontecer a cena".

A cena de "despedida de Madalena", embora reproduza quase que na totalidade os diálogos entre as personagens do romance, é um exemplo da leitura suplementar que o filme realiza do texto literário. Em plano fixo e sequencial, vemos Paulo Honório dormindo num banco da pequena capela que mandara construir na fazenda São Bernardo. Já tomado pelos ciúmes, Paulo Honório rumina formas de "vingar-se da mulher" e cobra desta explicação acerca das páginas rasgadas de uma carta, a qual, segundo o marido, Madalena havia escrito para outro homem (depois da morte da mulher, Honório descobre que a carta havia sido escrita para ele mesmo). Madalena entra no quadro e senta-se ao lado do marido. Entabulam um rápido diálogo, no qual se percebe as ambiguidades nas falas de Madalena, 
entre sinais de despedida e desilusão com o casamento. Madalena levanta-se e caminha para o fundo da cena, postando-se no lado esquerdo do quadro sob um foco de luz direcional, efeito fotográfico sutil que lhe confere, num nível simbólico, certa compleição aureolada e homenageia, em certo grau, sua caracterização de integridade ética, solidariedade para com os desvalidos e de resistência, mesmo que passiva, ao autocracismo do marido. Após proferir suas últimas palavras, postada no limiar entre o altar da capela e seus bastidores sombrios, o foco de luz se apaga e a vida de Madalena também. Aqui, Leon Hirszmam narra em imagens, sem explicitações diretas e evitando a tonalidade melodramática - e numa rigorosa economia de meios técnicos e estéticos -, um dos suicídios mais célebres e controversos da literatura mundial. É justamente o suicídio de Madalena que incita Paulo Honório a desviar sua atenção dos ciúmes e da acumulação material para a disposição ao relato.

Enfim, São Bernardo, de Leon Hirszmam é um exemplar incontornável das formas do diálogo entre filme e obra literária que revela como a adaptação pode retornar a um texto original e, ao mesmo tempo, utilizar as especificidades da linguagem cinematográfica suplementando-o com as diferenças estéticas e políticas características do cinema moderno.

Graciliano Ramos faleceu em 1953, antes de finalizar suas Memórias do cárcere. Ricardo Ramos, na "Explicação Final” do livro, conta que certa vez perguntou ao pai sobre o que trataria no epílogo das memórias. Diante da insistência, o escritor teria respondido que escreveria sobre as primeiras "sensações de liberdade", experimentadas após a saída da cadeia e ainda envoltas nos restos de prisão que continuavam a "acompanhá-lo em ruas quase estranhas". Podemos dizer que Nelson Pereira dos Santos, ao retornar às Memórias do Cárcere em 1984, parte justamente dessa indicação dada por Graciliano Ramos, para reinventar, em seu filme, as "sensações de liberdade" e suplementar, com liberdade autoral, as memórias do autor de Infância.

$\mathrm{Na}$ adaptação, Nelson Pereira dos Santos retorna ao estado de exceção, violência e brutalidade do período varguista descrito pelo narrador das Memórias, reinventando o personagem Graciliano Ramos que experimenta a condição absurda de ser prisioneiro sem culpa formal. O Graciliano Ramos de Nelson Pereira é coerente com o narrador do texto original, concebido sem qualquer traço de autocomiseração ou heroísmo martirizante. O personagem-Graciliano inventado por Nelson Pereira aparece 
movido por uma posicionalidade humanista e radical que explora os limites da subjetividade e do mundo absurdo à sua volta, numa caracterização que o aproxima dos anti-heróis sartreanos, para os quais somente a experiência pessoal é a chave para o "saber vivido". Como se sabe, com as filosofias da existência, de Soren Kierkergaard a Jean-Paul Sartre, a tradição do pensamento que privilegiava o objeto em detrimento da subjetividade se partiu. Não foi por acaso que, ao misturar-se à literatura, essa vertente teórica tenha dado aos gêneros Diário, Cartas, Confissões e Memórias um status literário elevado, entroncando as experiências singulares dos escritores pensadores e a reflexão sobre o mundo social. Aquilo que esses autores experimentaram na areia movediça da vida particular passou a ser matériaprima da reflexão filosófica, social e histórica. Esse foi o caso de Nietzsche, Marcel Proust, Franz Kafka, Elias Canetti, Albert Camus, Theodor Adorno, Eric Auerbach, Graciliano Ramos, Edward Said, entre outros.

Sem recorrer à estratégia da alegoria política ou do "discurso pela fresta”, Nelson Pereira, em seu Memórias do Cárcere, também estava tratando da repressão política e da função do intelectual naquele momento em especial, à época do processo de "redemocratização do país" e, portanto, ainda a partir do núcleo traumático das prisões e torturas impostas pela ditadura militar instalada em 1964. De certa forma, o filme fazia parte do corpus de obras que, no momento da abertura política no início dos anos 80, iniciava o longo processo de luto coletivo, o qual, como sabemos, ainda não terminou, mas que não deixava de ser uma forma de afirmar, mesmo precariamente, uma "sensação de liberdade". Como o diretor afirmou em entrevista, a "ideia foi fazer um filme no início da ditadura de 1964 para dizer 'tomem cuidado com a ditadura!' Mas eu tive que esperar vinte anos para dizer: 'viu como foi terrível a ditadura?".

A última sequência do filme de Nelson Pereira resume esta condição de transe político, quando explora as potências da liberdade, tanto as existenciais, quanto aquelas que dizem respeito à liberdade criativa do cineasta. Nela, Graciliano (Carlos Vereza) é visto escrevendo com um toco de lápis dado ao escritor pelo colega de prisão chamado Cubano. Os papéis usados para suas anotações, as quais o escritor afirmará como perdidas na abertura das Memórias, foram roubados por Gaúcho no almoxarifado do diretor da prisão. Por conta dessa transgressão, Gaúcho será “preso novamente", dessa vez na solitária. Embora o personagem não confesse o 
roubo ao diretor do presídio, nós, espectadores, sabemos do seu gesto transgressivo. Os outros presos, sabendo-se personagens do livro que Graciliano escreve ali diante dos seus olhos, cercam o escritor, aproximam seus corpos pois querem "entrar no papel roubado". Os agentes carcerários invadem o lugar em busca das anotações, pois sabem que Graciliano escreve sobre eles, sobre os presos e as condições carcerárias subumanas. Depois de uma batida geral no barracão, os guardas não apreendem os manuscritos. Os detentos sorrateiramente esconderam os papeis de Graciliano nas calças e cuecas, nos bolsos, sob as roupas sujas, colocando os manuscritos rentes a seus corpos, defendendo os originais como se fossem deles. Por conta desse espírito de corpo em liberdade, aqueles sujeitos, presos "comuns" ou "companheiros de viagem", os outros do olhar do escritor - o qual é o outro pelo olhar do cineasta -, participam e entram no livro.

Esse drible minoritário dado pelos detentos nos policiais durante o baculejo no barracão não está descrito nas Memórias de Graciliano, mas se tornou parte da mise-en-scène no filme. É exatamente essa liberdade de Nelson Pereira em "trair" o original e acrescentar essa cena final que o torna um intérprete mais "fiel”, digamos assim em consonância com o senso comum no trato com as adaptações, ao posicionamento político de Graciliano Ramos, indo além de qualquer transposição fílmica pretensamente "submissa" ao original. A cena diz estilizadamente aquilo que Graciliano Ramos escreve no início livro: as anotações ficaram sob o estrado de um catre na Colônia Correcional e se perderam. Contudo, no filme, os manuscritos são salvos, uma vez que ficam nos corpos dos companheiros de prisão, pois estes existem no corpo do livro escrito por Graciliano Ramos dez anos após sua libertação. Ao entrarem para o livro, portanto, os presos são, em nível simbólico, "libertados" da colônia penal.

Há outros momentos, ao longo do filme, nos quais o diretor maneja os elementos específicos da linguagem cinematográfica para traduzir e comentar o projeto ético e estético do escritor alagoano, sem, no entanto, qualquer vontade de mimetizar de forma naturalista o conteúdo do livro. Um exemplo é a sequência ambientada no navio Manaus, quando da transferência de Graciliano Ramos e de outros presos do Recife para a Casa de Detenção no Rio de Janeiro. Aqui, as artimanhas da montagem, da mise-en-scène, de som e imagem, manifestam as possibilidades suplementares que as relações entre texto literário e cinema podem produzir. Graciliano é visto preso no porão do 
navio juntamente com outros detentos. Na parte superior, no convés do navio, os viajantes "livres" observam, a partir de cima, o "espetáculo" dos párias, que compartilham uma garrafa de cachaça. Entre os presos se encontram tanto os militantes comunistas, que participaram de um levante de Natal, no Rio Grande do Norte, e foram presos em Maceió juntamente com Graciliano Ramos, quanto os "presos comuns", ladrões, assaltantes etc. A cachaça havia sido "roubada" ou comprada furtivamente da primeira classe, não se sabe bem. A divisão coletiva da bebida é mostrada de forma a reforçar uma solidariedade minoritária, uma indistinção social entre presos políticos e comuns. Um dos presos sob a influência da bebida, entre alegre e melancólico, começa a entoar o Canto da ema, contagiando a todos que entram num canto uníssono. O coro extrapola a fronteira do porão e chega aos ouvidos dos que estão "por cima". Os passageiros "de cima" sorriem e se apressam a ver os presos lá "de baixo", que cantam e xingam ao mesmo tempo. Os "de lá de cima" aplaudem aquele canto da ema, que ganha a força de um hino melancólico, porém atravessado pelo entusiasmo dos presos, como uma "canção de trabalho" capaz de sublimar a dor em potência poética.

A cena no livro não se dá desse modo, mas está representada no filme de forma ampliada numa tradução que é ao mesmo tempo acréscimo e perda em relação ao texto literário original, nunca transposição literal, de resto impossível. Graciliano observa silenciosamente e seu olhar destaca outro personagem, um preso que havia sido torturado e que, deitado em uma rede ao fundo do porão, canta, alquebrado pela violência, quase sem mover os lábios. Há nessa relação entre os espaços inferior e superior do cenário, entre os presos e os cidadãos livres "por cima", um diagrama imagético que funciona como uma metonímia das relações sociais assimétricas do período da ditadura varguista, mas que extrapola, sem o recurso ao panfletarismo rasteiro, o próprio tempo diegético do filme. Nessa sequência emblemática do filme, o estilo "clássico" de Nelson Pereira mobiliza o recurso da montagem em campo e contracampo, o lugar da memória individual é representado como "a parte de um todo", porão e convés funcionam como espaços de conflitos de classes, portanto, como representação metonímica das relações sociais do Brasil.

Nos níveis estéticos e formais, Memórias é menos experimental, digamos assim, que os mais densos, em termos de composição e linguagem, Vidas Secas e São Bernardo. A narrativa é linear e as relações entre som e imagem mais de acordo com a linguagem clássica e o realismo social. 
Contudo, há sutis efeitos de corrosão e ironia que relativizam esse corte "clássico", a exemplo da utilização do Hino Nacional como moldura da narrativa, uma das "liberdades" que o diretor, mesmo coerente como o estilo límpido de Graciliano Ramos, tomou em relação ao texto original. Primeiro, por sabermos que na crônica biográfica do escritor Graciliano Ramos ele deixou registrado o seu desejo individual de não executar o Hino Nacional e sua oposição a patriotismos imbecis, levando a uma atitude pública e institucional quando fora diretor da Instrução Pública no estado das Alagoas.

Podemos concluir que, no sentido dos deslocamentos culturais e do transe ético ao trânsito estético destas obras, há como que um fio de alta tensão política e cultural que liga e atravessa as traduções cinematográficas de Vidas Secas, São Bernardo e Memórias do cárcere em diálogo direto com o projeto estético, político e ético que Graciliano Ramos reiventou dos modernistas para ler o Brasil, diálogo este que ainda é contemporâneo das atuais crises éticas e estéticas que atravessam o país.

\section{Referências}

ALBUQUERQUE Jr., Durval Muniz de. A Invenção do Nordeste e outras artes. São Paulo: Cortez, 2001.

AVELAR, Idelber. Alegorias da derrota: a ficção pós-ditatorial e o trabalho de luto na América Latina. Belo Horizonte: Editora UFMG, 2003.

BRAZIEL, Jana Evans, MANNUR, Anita. Theorizing diáspora: a reader. Oxford, UK: Blackwell Publishing, 2003.

CANDIDO, Antônio. Tese e Antítese: ensaios. São Paulo: Editora Nacional, 1964.

CANDIDO, Antônio. Ficção e confissão: ensaios sobre Graciliano Ramos. Rio de Janeiro: Ed. 34, 1992.

FABRIS, Mariarosario. Nelson Pereira dos Santos: um olhar neo-realista? São Paulo: Edusp, 1994.

GILROY, Paul. O Atlântico negro: modernidade e dupla consciência. Trad. Cid Knipel. São Paulo: Editora 34; Rio de Janeiro: Universidade Candido Mendes, Centro de Estudos Afro-asiáticos, 2001.

GUIMARÃES, Jubireval Alencar. Graciliano Ramos e a fala das memórias. Maceió: EDICULTE/SECULTE, 1987. 
MORAES, Malu. Perspectivas estéticas do cinema brasileiro: seminário. Brasília: Editora Universidade de Brasília/Embrafilme, 1986.

NAFICY, Hamid. Situando o cinema com sotaque. In: FRANÇA; LOPES (Org.). Cinema, globalização e interculturalidade. Chapecó, SC: Argos, 2010.

RAMOS, Graciliano. Cartas. Rio de Janeiro: Record, 1981.

RAMOS, Graciliano. Infância. Rio de Janeiro: Record, 1995.

RAMOS, Graciliano. Memórias do cárcere. Prefácio de Nelson Werneck Sodré; Ilustrações de Percy Deane. 13a ed. Rio, São Paulo: Record, 1980. 2v. Ilust.

RAMOS, Graciliano. São Bernardo. Rio de Janeiro: Record, 2004.

SADIER, Darlene J. Nelson Pereira dos Santos. Trad. Cid Vasconcelos. Campinas, SP: Papirus, 2012.

SALEM, Helena. Nelson Pereira dos Santos: o sonho possível do cinema brasileiro. Rio de Janeiro: Nova Fronteira, 1987.

SALEM, Helena. Leon Hirszman: o Navegador das Estrelas. Rio de Janeiro: Rocco, 1997.

TOLENTINO, Célia Aparecida Ferreira. O Rural no cinema brasileiro. São Paulo: Editora UNESP, 2001.

XAVIER, Ismail. O Olhar e a voz: a narração multifocal do cinema e a cifra da história em São Bernardo. Revista da USP, no 2, 1997.

Recebido em 30 de abril de 2018.

Aceito em 28 de maio de 2018. 